\title{
The Application of Fuzzy C-Means Clustering For Agent Mapping
}

\author{
Yohan Alief Rizaldy1); (wan Ady Prabowo2); Sri Siswanti ${ }^{3)}$ \\ 12)3)Program Studi Informatika, STMIK Sinar Nusantara \\ 1)yohan.rizal95@gmail.com; 2)iwanadyp@sinus.ac.id; ${ }^{3)}$ syswanty@sinus.ac.id;
}

\begin{abstract}
Business competition in providing mountain equipment and selling the same product is caused the seller need to mapping and finding out the priority agents. Fuzzy C-means is one of the grouping data techniques which is the existence of each data point in a cluster is determined by the level of membership. The purpose of this study is to design and to make applications for grouping agents. This research method is used interview to find out the information about the data of goods ordering. The design model is used the System Development Life Cycle (SDLC). The system design method is used the Unified Modeling Language (UML). Agent mapping system with web-based fuzzy c-means clustering uses the PHP and MySQL programming languages as the database. The result of this study shows that there are three data clusters from 30 data agent that can be used to support the decisions for priority. They are first cluster consists of 15 agents, second cluster consists of 1 agent, and third cluster consists of 14 agents.
\end{abstract}

Keywords: Clustering, Fuzzy C-Means, Agent Mapping.

\section{PENDAHULUAN}

OA STORE merupakan usaha dibidang peralatan gunung, peralatan climbing, dan peralatan keselamatan yang disisi lain juga menerima pembuatan baju, celana, jaket, kantong tidur, matras, dan lain sebagainya dan telah memiliki 30 agen yang tersebar di wilayah Jawa Tengah. perusahaan harus mempunyai strategi dalam penjual produk dan perbaikan layanan atau prioritas agen. Salah satunya adalah dengan melakukan pemetaan / pengelompokan agen. Tentunya dengan melihat agen yang berpotensi untuk menjadi agen prioritas, sehingga perusahaan dapat mempertahankan dan memberikan pelayanan agen prioritas tersebut dengan cara memberikan pelayanan prima, reward, disisi lain sebagai target utama dalam promosi produk baru.

Penelitian ini untuk mengetahui bagaimana penerapan metode Fuzzy C-means Clustering (FCM) untuk pengelompokkan agen di $O A$ STORE.

Metode Fuzzy C-means Clustering (FCM) adalah suatu teknik pengclusteran data yang mana keberadaan tiap-tiap titik data dalam suatu cluster ditentukan oleh derajat keanggotaan. Fuzzy C-means Clustering (FCM) menggunakan model pengelompokan fuzzy dengan indeks kekaburan menggunakan Euclidean Distance sehingga data dapat menjadi anggota dari semua kelas atau cluster yang terbentuk dengan derajat keanggotaan yang berbeda antara 0 hingga 1 [1].

\section{TINJAUAN PUSTAKA}

2.1 Clustering

Clustering merupakan suatu metode pengelompokan berdasarkan ukuran kedekatan (kemiripan). Cluster pengelompokannya berdasarkan pada kedekatan dari suatu karakteristik sample yang ada, salah satunya dengan menggunakan rumus jarak euclidean. Dalam mengidentifikasi suatu permasalahan atau pengambilan keputusan Clustering selalu tidak harus sama persis akan tetapi cenderung memiliki kemiripan saja [2].

\subsection{Unified Modeling Language}

UML singkatan dari Unified Modeling Language yang berarti bahasa pemodelan standar. UML juga dapat diartikan sebagai bahasa yang memiliki sintaks dan semantik [3].

Unified Modeling Language / UML merupakan salah satu standar bahasa yang banyak digunakan di dunia industri untuk mendefinisikan requirement, membuat analisis dan desain, serta menggambarkan arsitektur dalam pemrograman berorientasi objek [4].

\subsection{Fuzzy C-Means Clustering}

Algoritma ini merupakan salah satu teknik soft computing yang paling popular dengan menggunakan pendekatan data point dimana titik pusat cluster akan selalu diperbaharui sesuai dengan nilai keanggotaan dari data yang ada dan selain itu algoritma fuzzy c-means juga 
merupakan algoritma yang bekerja dengan menggunakan model fuzzy sehingga memungkinkan semua data dari semua anggota kelompok terbentuk dengan derajat keanggotaan yang berbeda antara 0 dan 1 [5].

Cara kerja atau tahapan kerja dari algoritma fuzzy c-means clustering adalah sebagai berikut:

1. Masukkan data yang akan dicluster berupa matriks $X$ berukuran $n \times m$ ( $n=$ banyaknya sampel data dan $\mathrm{m}=$ banyaknya variable setiap data). $X \mathrm{ij}=$ data sampel ke-i $(i=1,2, \ldots ., n)$, variabel ke-j $(j=1,2, \ldots . ., m)$

2. Tentukan

- Banyaknya kluster yang akan dibentuk (c)

- Pangkat pembobot (w)

- Maksimum iterasi (Maxltr).

- Error terkecil $(\xi)$

- Fungsi obyektif awal $(\mathrm{P} 0=0)$

- Iterasi awal $(t=1)$

3. Bangkitkan matriks partisi awal Unxc = [ $\mu i k], \mu i k$ yaitu bilangan random yang menyatakan suatu derajat keanggotaan. ( bisa menggunakan rumus excel random, Dimana nilai dari keanggotaan terletak pada interval $0-1$ )

4. Hitung pusat cluster ke-k $\left(\mathrm{V}_{\mathrm{kj}}\right)$ dengan $\mathrm{k}=1,2, \ldots . ., \mathrm{c} ;$ dan $\mathrm{j}=1,2, \ldots, \mathrm{m}$ sebagai berikut :

$V_{k j}=\frac{\sum_{i=1}^{n}\left(\mu_{i k}\right)^{w} \cdot X_{i j}}{\sum_{i=1}^{n}\left(\mu_{i k}\right)^{w}}$

5. Hitung fungsi obyektif pada iterasi ke-t, Pt, yang menggambarkan jumlah jarak data ke pusat cluster.

$\mathrm{P}_{\mathrm{t}}=\sum_{\mathrm{i}=1}^{\mathrm{n}} \sum_{\mathrm{i}=1}^{\mathrm{c}}\left(\left[\sum_{\mathrm{j}=1}^{\mathrm{m}}\left(\mathrm{X}_{\mathrm{ij}}-\mathrm{V}_{\mathrm{kj}}\right)^{2}\right]\left(\mu_{\mathrm{ik}}\right)^{\mathrm{w}}\right)$

Dengan

$P_{t}=$ fungsi obyektif;

$\mathrm{X}_{\mathrm{ij}}=$ elemen $\mathrm{X}$ baris $\mathrm{i}$, kolom $\mathrm{j}$;

$\mathrm{V}_{\mathrm{kj}}=$ pusat cluster

6. Perbaiki derajat keanggotaan matriks partisi :

$\mu_{i k}=\frac{\left[\sum_{j=1}^{n}\left(X_{i j}-V_{k j}\right)^{2}\right]^{\frac{-1}{w-1}}}{\left.\sum_{k=1}^{c}\left[\sum_{j=1}^{m}\left(X_{i j}-V_{k j}\right)^{2}\right)\right]^{\frac{-1}{w-1}}}$

dengan :

$\mathrm{i}=1,2, \ldots \ldots, \mathrm{n}$

$\mathrm{k}=1,2, \ldots \ldots, \mathrm{c}$

$\mathrm{Xij}=$ sampel data ke-i, variabel ke-j

Vkj=pusat cluster ke-k untuk variabel ke-j

$\mathrm{w}=$ pangkat pembobotan

7. Cek kondisi berhenti
- Jika $\left(\left|P_{t}-P_{t-1}\right|<\xi\right)$ atau (t > Maxiter) maka berhenti;

- Jika tidak: $\mathrm{t}=\mathrm{t}+1$, ulangi langkah ke-4 [5].

\subsection{Penelitian Terkait}

Penelitian yang terkait antara lain :

Penelitian yang dilakukan oleh Wiji Lestari dengan judul Pemetaan Gaya Belajar Mahasiswa Dengan Clustering Menggunakan Fuzzy C-Means membahas tentang mengelompokkan objek-objek berdasarkan karakteristik diantara objek-objek tersebut, dengan menggunakan kriteria Visual, Verbal, Aural, Physical, Logical, Social dan Solitary [6].

Penelitian yang dilakukan oleh Ariyady Kurniawan, Made Sudarma dengan judul Penerapan Fuzzy C-Means Untuk Penentuan Besar Uang Kuliah Tunggal Mahasiswa Baru masalah yang dibahas tentang UKT (Uang Kuliah Tunggal) yaitu merupakan sebagian BKT (Biaya Kuliah Tunggal) yang ditanggungkan kepada setiap mahasiswa berdasarkan kemampuan ekonominya [7].

\section{METODE PENELITIAN}

Penelitian ini merupakan penelitian exsperimental dengan tahapan penelitian yaitu analisa, desain, pengkodean, pengujian dan implementasi. Tahap Analisa sistem melakukan pengamatan tentang proses bisnis yang berjalan di PT. OA STORE. Dari tahapan ini mendapatkan data transaksi masing - masing agen. Desain sistem menggunakan Unifed Modelling Language (UML) meliputi Diagram Use Case, Diagram Class dan Pemodelan menggunakan fuzzy c-means clustering. Tahap pengkodean ini tentang software dan hardware yang digunakan pada penelitian.Tahap pengujian dengan Hasil dari perhitungan dibandingkan untuk mengetahui validitas dari fuzzy c-means clustering. Hasil yang didapatkan nantinya dapat digunakan untuk membantu marketing/reseller mendapatkan informasi tentang kelayakan agen dan mengetahui kategori setiap agen apakah tergolong dalam prioritas rendah, sedang, atau tinggi.

\section{HASIL DAN PEMBAHASAN \\ 4.1 Analisa sistem}

Tahap Analisa sistem melakukan pengamatan tentang proses bisnis yang berjalan di PT. OA STORE. Dari tahapan ini 
mendapatkan data transaksi masing - masing agen berupa atribut yang meliputi data agen setiap agen yaitu nama agen, data order barang (kaos, celana, jaket, sleeping bag, tenda, sepatu, sandal).

Tabel 1. Data Agen

\begin{tabular}{|c|c|c|c|c|c|c|c|c|}
\hline \multirow[b]{2}{*}{ No } & \multirow[b]{2}{*}{ Nama } & \multicolumn{7}{|c|}{ Barang Di Order } \\
\hline & & 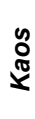 & $\frac{\pi}{\frac{\pi}{\delta}}$ & $\frac{\pi}{\pi}$ & 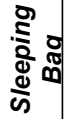 & 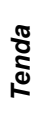 & 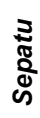 & 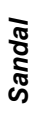 \\
\hline 1 & Agen 1 & 1 & 3 & 4 & 4 & 1 & 0 & 1 \\
\hline 2 & Agen 2 & 0 & 2 & 2 & 1 & 2 & 2 & 1 \\
\hline 3 & Agen 3 & 2 & 2 & 3 & 1 & 2 & 2 & 3 \\
\hline .. & $\ldots$ & .. &.. & ... &.. & ... & ... & ... \\
\hline 30 & Agen 30 & 0 & 0 & 3 & 2 & 2 & 2 & 2 \\
\hline
\end{tabular}

\subsection{Desain Sistem}

Tahap desain sistem dengan UML di PT. OA STORE menggunakan Use Case Diagram dan Class Diagram.

\subsubsection{Use Case Diagram}

Aktor yang terlibat dalam Use Case Diagram ini yaitu Admin, mulai dari melakukan login, mengelola pelanggan/agen, pemetaan dan penerapan Fuzzy C-mean Clustering. Aktor Admin dapat berinteraksi dengan sistem dapat dilihat pada Gambar 1.

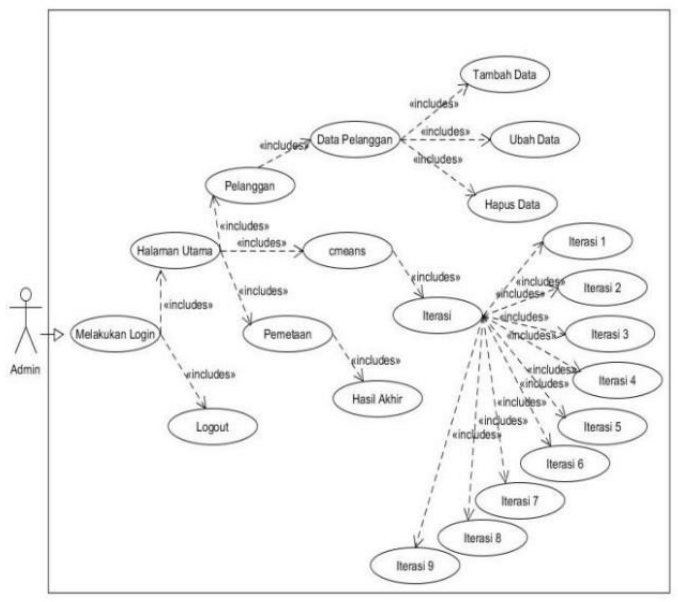

Gambar 1. Use Case Diagram Aktor Admin dapat berinteraksi dengan system

\subsubsection{Class Diagram}

Class Diagram Pengelompokan Agen terdapat kelas main, Login, cmn_users, cmn_pelanggan, i1_appc, i1_bppc_sum, i1_cpfo, i1_ekspl, i1_dmpu. Class diagram terlihat pada Gambar 2.

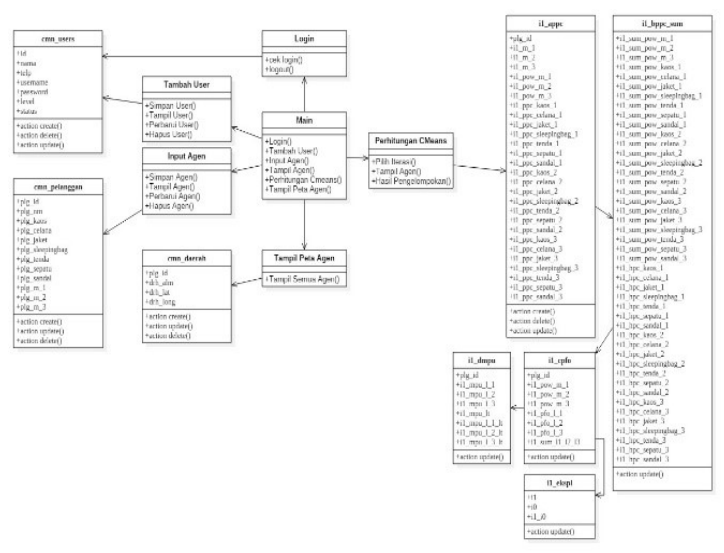

Gambar 2. Class Diagram Pengelompokan Agen

\subsection{Pemodelan Data dengan fuzzy c-means clustering}

Penerapan metode Fuzzy C-means Clustering (FCM) untuk pengelompokkan agen studi kasus di OA STORE sebanyak 30 transaksi pada bulan Januari 2015.

1. Data sampel

Data sampel yang digunakan adalah data sampel agen, sesuai pada tabel 1 .

2. Penentuan Nilai Parameter Awal Jumlah cluster $(\mathrm{c})=3$; Pangkat $(W)=2$; Maksimum $(\xi)$ Iterasi (Maxlter) $=10$; Error terkecil $=0.1$; Fungsi objektif awal $\left(P_{0}\right)=0$; Iterasi awal $(\mathrm{t}) \quad=1$.

3. Membangkitkan bilangan random Matriks Partisi Awal

$$
U=\left(\begin{array}{ccl}
0,548 & 0,268 & 0,731 \\
0,957 & 0,604 & 0,475 \\
0,928 & 0,344 & 0,100 \\
\ldots & \ldots & \ldots
\end{array}\right)
$$

4. Menentukan pusat cluster

- Diketahui $\left(\mu_{i k}\right)^{w}=\left(\mu_{i 1}\right)^{2}=(0,548)^{2}=0,300$, seterusnya sampai alternative ke $\mathrm{n}$. Sehingga $\sum_{\mathrm{i}=1}^{\mathrm{n}}\left(\mu_{\mathrm{i} 1}\right)^{2}=10,939$. Hitung seterusnya hingga data terakhir.

- Hitung nilai $\left(\mu_{i 1}\right)^{2 *} X_{i 1}=0,300 * 1=0,300$, seterusnya sampai alternative ke $\mathrm{n}$, sehingga $\sum_{i=1}^{n}\left(\left(\mu_{i 1}\right)^{2} \cdot X_{i 1}\right) \quad=$ 22,492. Hitung seterusnya hingga data terakhir.

- Hitung pusat cluster ada setiap cluster dan atributnya :

$$
\begin{aligned}
-\mathrm{Vi} 1 & =\frac{\sum_{i=1}^{n}\left(\left(\mu_{i 1}\right)^{2} \cdot X_{i 1}\right)}{\sum_{i=1}^{n}\left(\mu_{i 1}\right)^{2}} \\
\text { - Vi1 } & =\frac{22,492}{10,939}=2,05612945(2,056)
\end{aligned}
$$




$$
\left.\begin{array}{ccccccc}
\multicolumn{8}{c}{\text { Nilai Pusat cluster }=V=} \\
2,056 & 2,231 & 2,182 & 2,02 & 2,398 & 3,17 & 1,776 \\
6,932 & 6,199 & 1,789 & 2,372 & 2,451 & 2,413 & 1,577 \\
2,245 & 2,397 & 1,884 & 2,392 & 1,815 & 2,196 & 2,091 \\
\ldots & \ldots & \ldots & \ldots & \ldots & \ldots & \ldots
\end{array}\right)
$$

5. Menghitung fungsi objektif

- Pertama, menghitung nilai $\left[\sum_{j=1}^{m}\left(X_{i j}-V_{k j}\right)^{2}\right]\left(\mu_{i k}\right)^{w}$ dengan hasil 21,12094892. Dan seterusnya sampai alternatif ke $\mathrm{n}$.

- Kedua, jumlah $\left[\sum_{j=1}^{m}\left(X_{i j}-V_{k j}\right)^{2}\right]\left(\mu_{i k}\right)^{w}$ dari dari setiap cluster. Sehingga $21,12094892+60,90656688+$ $15,10169685=97,12921265$

- Ketiga, menghitung total dari L1 + L2 + L3 sehingga diperoleh nilai fungsi objektif 20621,89045

\begin{tabular}{|c|c|c|c|}
\hline 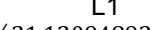 & L2 & L3 & $+\mathrm{L} 2+\mathrm{L} 3$ \\
\hline 1,12094892 & 60,90656688 & 15,10169685 & 97,12921265 \\
\hline 7,434754086 & 68,10087067 & 7,488437901 & 83,02406266 \\
\hline 4,585803487 & 45,91366886 & 3,482277686 & 53,98175004 \\
\hline$\cdots$ & .. & ... & \\
\hline
\end{tabular}

Perhitungan fungsi objektif $P_{t}=$

6. Menghitung perubahan matriks partisi

- Pertama, menghitung nilai $\left[\sum_{i=1}^{\infty}\left(x_{i},-v_{i}\right)^{z}\right]$ $=0,046420649$, dan seterusnya sampai alternatif ke $n$.

- Kedua, menghitung total dari langkah satu, $\left.\quad \sum_{k=1}^{c}\left[\sum_{j=1}^{m}\left(X_{i j}-V_{k j}\right)^{2}\right)\right]^{\frac{-1}{w-1}}=$ 0,12663077

- Ketiga, menghitung nilai dari $\mu_{\mathrm{ik}}$ dari setiap data.

$$
\begin{aligned}
& \mu_{\mathrm{i} 1}=\frac{0,046420649}{0,12663077} \\
& \mu \mathrm{i} 1=0,366583
\end{aligned}
$$

Dan seterusnya hingga data terakhir, dan terbentuk matrik partisi yang baru, dan digunakan untuk iterasi yang berikutnya.

Matriks Partisi Baru Hasil Langkah 6 Pertama, Kedua : $\mu$ ik

$\begin{array}{lllll}\text { L1 } & \text { L2 } & \text { L3 } & \text { L1+L2+L3 }\end{array}$ $\mu i k=\left(\begin{array}{ccc}0,046420649 & 0,01633565 & 0,063874471 \\ 0,133593225 & 0,01463861 & 0,118909213 \\ 0,208601832 & 0,020965041 & 0,232519992 \\ \ldots . . & \ldots . . & \ldots . .\end{array}\right) \rightarrow \begin{gathered}0,12663077 \\ 0,267141048 \\ 0,462086865 \\ \ldots\end{gathered}$

7. Mengecek kondisi berhenti

- Jika nilai $(|\mathrm{Pt}-\mathrm{Pt}-1|<\xi)$ atau $(\mathrm{t}>$ Maxlter) maka berhenti

- Jika tidak $\mathrm{t}=\mathrm{t}+1$, mengulang langkah

\begin{tabular}{|c|c|c|c|c|}
\hline \multicolumn{5}{|c|}{ Matriks partisi ke $9=$ Maxlter } \\
\hline & 0,487475238 & 0,001937472 & $0,510587291)$ & 0,510587291 \\
\hline & 898945 & 0,000910981 & 0,468190074 & 0,530898945 \\
\hline & & $0,0005 / 17.05$ & 0,465352699 & 0,534069598 \\
\hline
\end{tabular}
ke 4
Karena pada studi kasus ini Maxlter $=9$, maka didapat nilai matrik partisi

\subsection{Pengkodean/Konstruksi}

Tahap pengkodean ini tentang software dan hardware yang digunakan pada pembuatan aplikasi. Berikut ini adalah hasil tampilan output sistem.

\subsubsection{Tampilan Fuzzy C-means Clustering (FCM)}

Terlihat pada Gambar 3, Gambar 4, dan Gambar 5, tampilan halaman Fuzzy C-means Clustering (FCM) akan menampilkan perhitungan dari iterasi 1 sampai iterasi 9 . Disertai perhitungan pusat cluster, perhitungan fungsi objek, perhitungan matriks partisi u, dan kesimpulan dari tiap tiap iterasi.

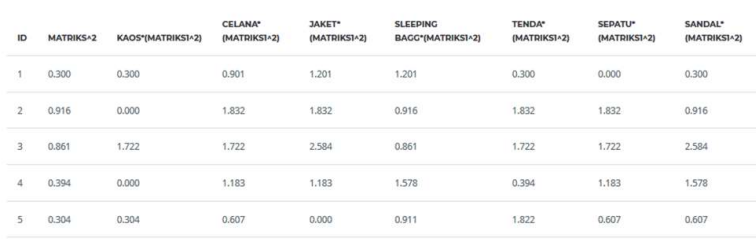

Gambar 3. Tampilan Perhitungan Pusat Cluster pada Fuzzy C-means Clustering (FCM)

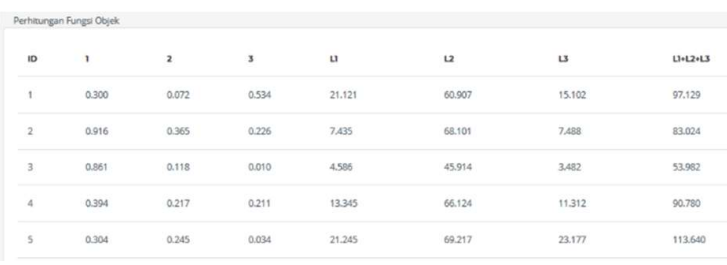

Gambar 4. Tampilan Perhitungan Fungsi Objek pada Fuzzy C-means Clustering (FCM)

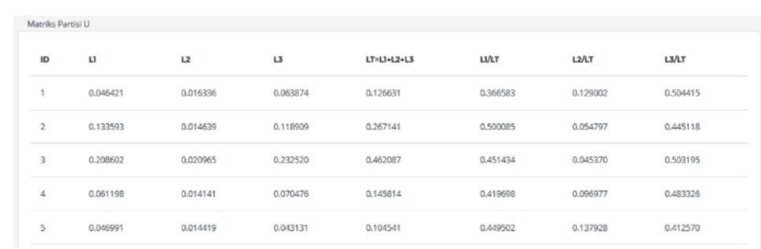

Gambar 5. Tampilan Perhitungan Matriks Partisi U pada Fuzzy C-means Clustering (FCM)

Tampilan perhitungan Fuzzy C-means Clustering (FCM) setelah memilih nilai awal, ditujukan pada Gambar 6. 


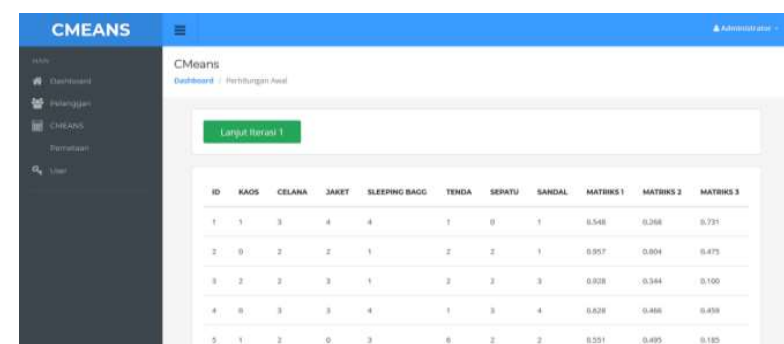

Gambar 6. Proses hitung Fuzzy C-means Clustering (FCM)

\subsection{Pengujian dan Implementasi Sistem}

Tabel 2 Menunjukkan pengujian validitas dilakukan untuk menyesuaikan apakah perhitungan excell dengan perhitungan sistem didapatkan hasil yang sama. Hasil perhitungan sistem dan perhitungan excell mendapatkan hasil jumlah yang sama.

Tabel 2. Pengujian validitas

\begin{tabular}{|c|l|c|c|c|}
\hline No & Nama Pelanggan & $\begin{array}{c}\text { Hasil } \\
\text { Excel } \\
\text { (Cluster) }\end{array}$ & $\begin{array}{c}\text { Hasil } \\
\text { Sistem } \\
\text { (Cluster) }\end{array}$ & Hasil \\
\hline 1 & Agen Pertama & 3 & 3 & Valid \\
\hline 2 & Agen Kedua & 1 & 1 & Valid \\
\hline 3 & Agen Ketiga & 1 & 1 & Valid \\
\hline 4 & Agen keempat & 3 & 3 & Valid \\
\hline.. & $\ldots$. & $\ldots$ & $\ldots$ & \\
\hline 30 & Agen ketigapuluh & 1 & 1 & Valid \\
\hline
\end{tabular}

Implementasi sistem merupakan proses pembuatan sistem berupa perancangan aplikasi pemetakan agen di OA store. Pada halaman pemetakan, jika data sudah diolah atau sudah di proses di c-means, data akan tampil di pemetakan berupa maps dan pin berwarna. Adapun tampilannya sebagai Gambar 7.

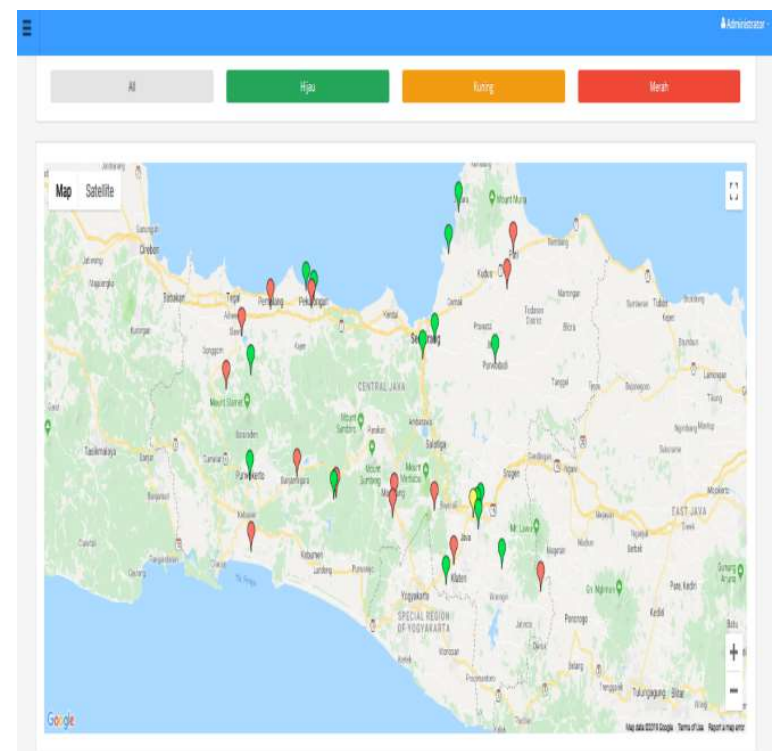

Gambar 7. Pemetakan dan Pin
Hasil Clustering Fuzzy C-means Clustering (FCM) terlihat pada Kelompok pertama rendah (Cluster ke-1) berisi 15 agen yaitu : Agen 2, Agen 3, Agen 5, Agen 6, Agen 7, Agen 8, Agen 9, Agen 16, Agen 18, Agen 19, Agen 20, Agen 23, Agen 24, Agen 25, Agen 30. Pada Kelompok kedua sedang (Cluster ke-2) berisi 1 agen yaitu Agen 26. Sedangkan pada kelompok ketiga tinggi (Cluster ke-3) berisi 13 agen yaitu: Agen 1, Agen 4, Agen 10, Agen 11, Agen 12, Agen 13, Agen 14, Agen 15, Agen 17, Agen 21, Agen 22, Agen 27, Agen 28, dan Agen 29. Hasil Clustering terlihat pada Gambar 8 berikut.

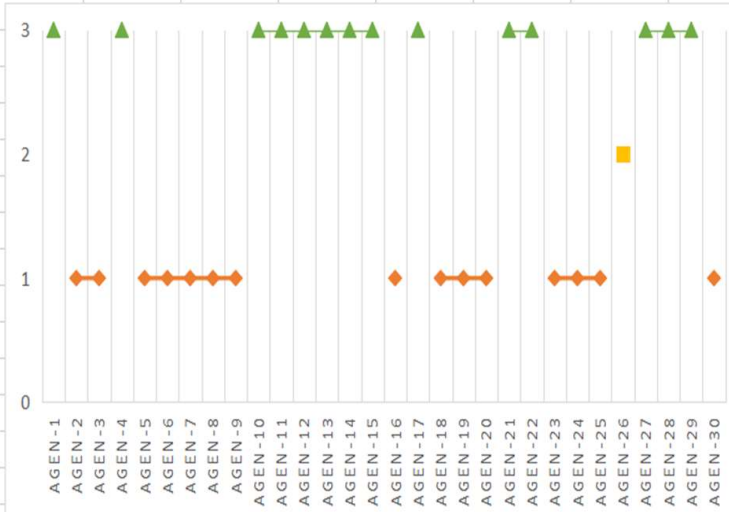

Gambar 8 Grafik hasil Cluster masing-masing Agen dengan Fuzzy C-means Clustering (FCM)

\section{PENUTUP}

Berdasarkan hasil pembahasan yang telah dilakukan pada bab sebelumnya maka kesimpulannya adalah telah terbangunnya Sistem Pemetakan Agen di PT OA Store Industri Indonesia guna membantu marketing/reseller mendapatkan informasi tentang kelayakan agen dan mengetahui kategori setiap agen apakah tergolong dalam prioritas rendah, sedang, atau tinggi.

Penelitian tentu saja masih mempunyai kekurangan Masih banyak hal yang dapat dilakukan untuk mengembangkan aplikasi ini agar menjadi lebih baik, saran dalam penelitian ini adalah Ketepatan dalam proses input data perlu diperhatikan agar tidak terjadi kesalahan dalam proses perhitungan. Input data disarankan selalu rutin dilakukan pembaharuan maksimal 1 tahun sekali agar data yang dihasilkan up to date.

\section{DAFTAR PUSTAKA}

[1] K. and P. , Aplikasi Logika Fuzzy untuk Pendukung Keputusan, Yogyakarta: Graha IImu, 2010. 
[2] E. Hadinata, "Metode Clustering Algoritma Fuzzy CMeans," 19 Desember 2013. [Online]. Available: https://edrianhadinata.wordpress.com/20 13/12/19/metode-clustering-algoritmafuzzy-cmeans/.

[3] P. P. Widodo and H. , Menggunakan UML, Bandung: Informatika, 2011.

[4] R. A. Soekamto and M. Shalahuddin, "Rekayasa Perangkat Lunak Terstruktur Dan Berorientasi Objek," Informatika, Bandung, 2013.

[5] D. J. Bora and A. K. Gupta, "International Journal of Computer Trends and Technology (IJCTT)," A Comparative study Between Fuzzy Clustering Algorithm and Hard Clustering Algorithm, pp. 108113, 2014.

[6] W. Lestari, "Pemetaan Gaya Belajar Mahasiswa Dengan Clustering Menggunakan Fuzzy C-Means," Jurnal Sainstech Politeknik Indonusa Surakarta, pp. 1-8, 2015.

[7] A. K. Muchsin and M. Sudarma, "Penerapan Fuzzy C-Means Untuk Penentuan Besar," Lontar Komputer, pp. 175-183, 2015.

[8] U. Efiyah, Penerapan Algoritma Fuzzy CMeans Untuk Pengelompokan Harga Gabah di Tingkat Penggilingan Berdasarkan Kualitas Gabah, Malang: Universitas Islam Negeri Maulana Malik Ibrahim, 2014.

[9] R. M. Anggraeni, "Perbandingan Algoritma Apriori Dan Algoritma Fp-Growth Untuk Perekomendasi Pada Transaksi Peminjaman Buku Di Perpustakaan Universitas Dian Nuswantoro," pp. 1-5, 2015.

[10] M. S. Mustaqbal, R. F. Firdaus and H. Rahmadi, "Pengujian Aplikasi Menggunakan Black Box Testing Boundary Value Analysis," Jitter, vol. 1, pp. 31-36, 2015. 